\title{
Ética y propiedad industrial Algunas cuestiones sobre las patentes farmacéutit
}

Cecilia Pourrieux

mail : cecipo55@yahoo.com.ar

Marcelo Ramal

mail:marceloramal@gmail.com

\section{Resumen}

Un factor importante para analizar la relación entre ética, salud, investigación y mercado, lo constituye la evolución histórica de las patentes medicinales. Las discusiones respecto del derecho de propiedad sobre los productos abstractos o conceptuales del trabajo humano emergieron en la etapa histórica caracterizada por lageneralización de la sociedad mercantil. Sin embargo, el derrotero que condujo a la imposición generalizada de patentes, a finales del siglo XIX, estuvo determinado por importantes polémicas económicasy filosóficas que tuvieron lugar desde un siglo antes, con el advenimiento del capitalismo industrial. Expondremos cómo se desarrollaron las controversias en torno a este problema, con el objeto de desmitificar al derecho de patentes como una expresión "natural" del desarrollo científico técnico. Por el contrario, buscaremos mostrar que el itinerario de los derechos de propiedad sobre el conocimiento resultó condicionado por circunstancias históricas y sociales precisas.

\section{Abstract}

An important factor in order to analyze the relationship between ethics, health, research and market is the historical evolution of medicinal patents. Debates regarding property rights over abstract or conceptual products of human labor emerged in the historical stage characterized by the generalization of

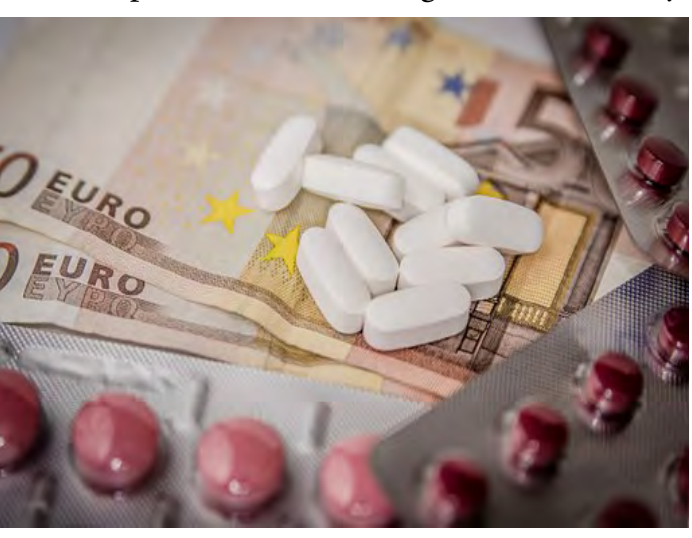

commercial society. However, the course that led to the widespread imposition of patents, at the end of the 19th century, was determined by important economic and philosophical controversies that since a century before have taken place, with the advent of industrial capitalism.

We will explain how the controversies around this problem developed, so as to demystify the patent law as a "natural" expression of technical scientific development. On the contrary, we will seek to show that the itinerary of property rights over knowledge was conditioned by precise historical and social circumstances.

Marcelo Ramal (UNQ - UBA) Lic. en Economía,Profesor asociado en Historia del Pensamiento Económico, Facultad de Ciencias Económicas de la UBA. Profesor Adjunto de la misma materia en la UNQ.

Cecilia Pourrieux (UNLa) ORCID iD: 0000-0003-3643-214X 
El problema de las patentes medicinales y el análisis histórico de su evolución a lo largo del tiempo, contribuye a entender la relación entre ética, salud, investigación y mercado.

Las discusiones respecto del derecho de propiedad sobre los productos abstractoso conceptuales del trabajo humano emergieron en la etapa histórica caracterizada por la generalización de la sociedad mercantil. Sin embargo, el derrotero que condujo a la imposición generalizada de patentes, a finales del siglo XIX, estuvo determinado por importantes polémicas económicas y filosóficas que tuvieron lugar desde un siglo antes, con el advenimiento del capitalismo industrial. En efecto: las primeras tentativas de derechos de propiedad sobre el conocimiento tuvieron lugar sobre las obras literarias, y dan cuenta de ello las deliberaciones de la Asamblea Nacional de Francia de 1791, dos años después de la revolución francesa. Allí, Jean Le Chapelier, el cuarto presidente de la Asamblea, incluye al derecho de autor dentro de la filosofía del derecho natural, al caracterizar al "fruto del pensamiento del escritor" como "la más personal de todas las propiedades" (Bécourt D., 1990, p. 6) Este argumento, sin embargo, ha sido sometido a crítica. La más difundida de ellas señala que el pretendido control o potestad que un individuo posee respecto de sus ideas desaparece desde el momento mismo en que éstas son compartidas o comunicadas a terceros (Machlup F. y Penrose E., 1950, pp. 1-29)
Otro argumento que se esgrimió en la época citada es el de la recompensa o retribución que debe recibir toda persona en relación a los servicios que él mismo ha prestado a la sociedad, en este caso, una cierta invención. Contra este planteo, se ha cuestionado, muy acertadamente, que los inventos, que se presentan como un producto personal, tienen lugar en un contexto histórico y social determinado, sin el cual aún las ideas más innovadoras no podrían traducirse en avances tecnológicos o industriales efectivos. Ese contexto social, a su turno, está signado por el carácter crecientemente social o acumulativo de las innovaciones, donde la tarea de un cierto equipo de investigación se encuentra precedida o acompañada por los esfuerzos de otros. Por otra parte, se ha señalado también que una cierta retribución al inventor o innovador no implica necesariamente el monopolio de la invención, esto es, la imposición de una patente (Katz J., 1976).

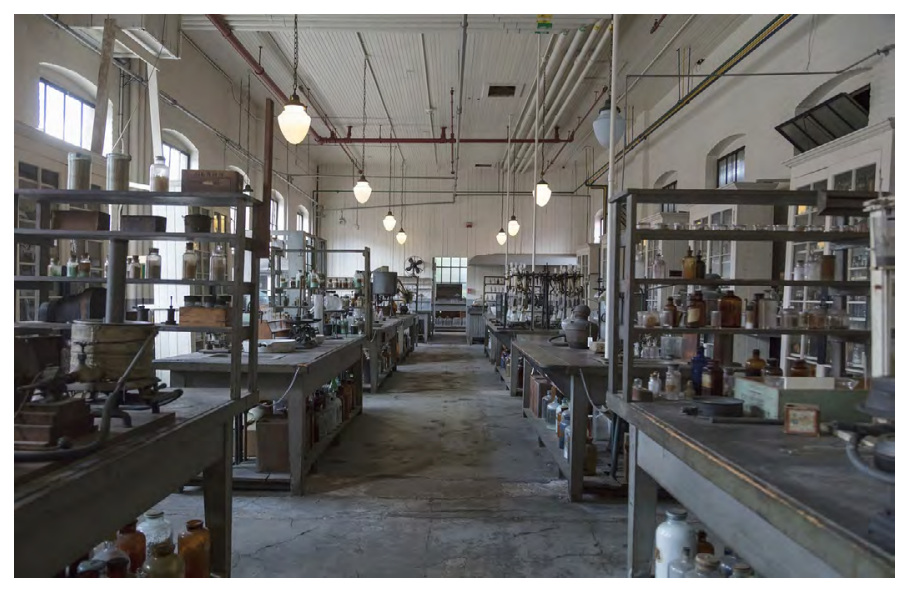

Un señalamiento vinculado al anterior relaciona a esa retribución o recompensa al inventor con el progreso social e industrial de carácter general. Según los que sostienen ese punto de vista, el derecho de patente actuaría como un incentivo para el desarrollo de mayores innovaciones. En oposición a ello, se ha argumentado sobre el carácter 
antagónico que existe entre derechos de propiedad sobre el conocimiento, de un lado, y el interés social general, del otro. Como ha señalado Joan Robinson (1958) al referirse a la paradoja de las patentes, frente al incentivo personal que implica el derecho de propiedad sobre la invención, ese mismo derecho bloquea, retrasa o bien encarece la difusión del progreso técnico al conjunto de la sociedad.

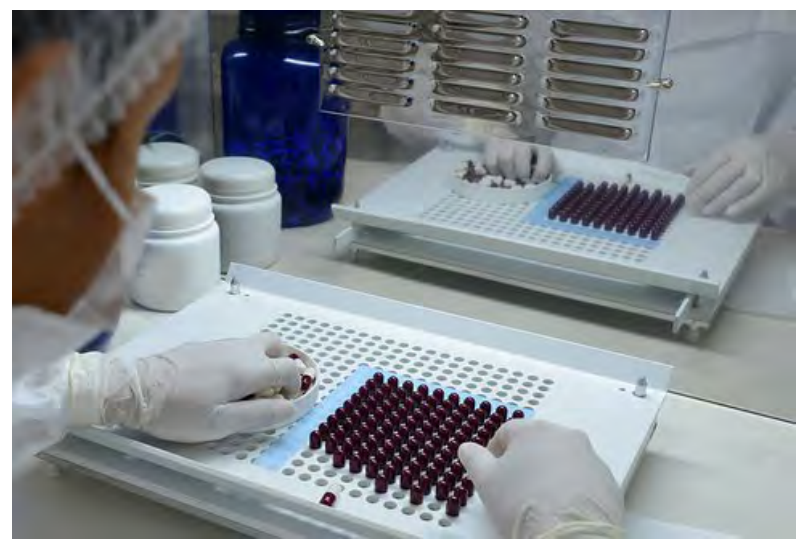

ciones en cuestión. Si una cierta idea puede ser fácilmente copiada, señalan, entonces el derecho de patentes es una imposición artificial e injusta, respecto de su difusión.

La breve exposición de estas controversias contribuye a desmitificar al derecho de patentes como una expresión "natural" del desarrollo científico técnico. Por el contrario, el itinerario de los derechos de propiedad sobre el conocimiento resul tó condicionado por circunstancias históricas y sociales precisas. Veamos cómo se desenvolvieron.

Durante la primera mitad del siglo XIX, cuando irrumpió con toda su fuerza el capitalismo industrial, el desarrollo de derechos de propiedad sobre la ciencia y la técnica aplicados a la producción, aquello que conocemos como 'propiedad industrial', no siguió un derrotero nítido. De un modo general, prevaleció la tendencia a la difusión de los inventos, por ejemplo, de maquinarias e instrumentos de trabajo. En esta concepción, se tuvieron en cuenta dos de los característicos argumentos opuestos a la fijación de derechos de propiedad sobre el conocimiento, que recién citamos. Por un lado, el carácter social o acumulativo de las innovaciones, donde ningún individuo podría arrogarse por entero, la autoría de una de ellas. Luego, esa difusión aparece asociada al capitalismo de libre competencia, que predominaba en el período citado.

Hacia las últimas décadas del siglo XIX, y precisamente con la emergencia de las grandes corporaciones y monopolios capitalistas, emerge una fuerte tendencia a la apropiación del conocimiento. Por otra parte, las grandes industrias comienzan a desarrollar sus propios laboratorios de investigación, una tarea que antes aparecía circunscripta al ámbito del Estado o de la academia. Es 
en este contexto que en 1883 se suscribe el Convenio de París para la Protección de la Propiedad Industrial. Debe tenerse en cuenta que el Convenio de París y los tratados sucesivos no se refieren ya a la figura del "inventor individual" sino que buscan proteger a la gran corporación capitalista, que ha integrado a sus filas al científico en tanto empleado, ejerciendo la apropiación integral de los resultados de su trabajo.

Reconocido como el primer régimen de patentes con alcance internacional, el Convenio estableció la igualdad de tratamiento para personas nativas y extranjeras en la concesión de estos derechos; la prioridad a un inventor para solicitar, una vez registrada la patente en un cierto país, el registro de la misma en el resto de los países firmantes de la Convención; el otorgamiento de licencias obligatorias por parte del inventor protegido, o sea, la explotación compulsiva, previo pago de derechos al propietario de la patente, de invenciones cuya difusión o uso hubiera sido restringido. En esta norma, se reconoce otro de los factores negativos del sistema de patentes, esto es, la limitación a la difusión del conocimiento sobre el conjunto de la sociedad. Como veremos enseguida, ello será un punto crucial en lo que respecta a las cuestiones vinculadas a los medicamentos y la salud humana. Finalmente, la Convención habilita a los titulares de la patente al comercio internacional de sus productos, con la debida protección de sus derechos de propiedad sobre los mismos.

El Convenio de París recibió sucesivas actualizaciones y revisiones en Bruselas (1900), Washington (1911) La Haya (1925), en Londres (1934), Lisboa (1958), Estocolmo
(1967) y 1979. De un modo general, este sistema legislativo ha sido criticado como un recurso para asegurar el monopolio tecnológico de los países industriales, y consolidar el retraso relativo de las naciones atrasadas. Probablemente por esto mismo, estos últimos países buscaron sortear, bajo diferentes recursos, el cumplimiento estricto del régimen de derechos de patentes, aun cuando formalmente adhirieran a los mismos. Para limitar decisivamente estas excepciones a las normas de la Convención de París, se produjo un reforzamiento cualitativo de los derechos de propiedad sobre el conocimiento con la aprobación de los Aspectos del Derecho de Propiedad Intelectual vinculados con el Comercio (ADPIC, o TRIPS en inglés. En castellano: Acuerdo sobre los Aspectos de los Derechos de Propiedad Intelectual relacionados con el Comercio).

Hasta esemomento, la adhesión al Convenio de París y sus revisiones sucesivas no había sido ratificada por numerosos países, en particular, de la llamada periferia. Un aspecto central de esta adhesión parcial residía precisamente en la renuencia a adscribir a parámetros rígidos de reconocimiento de derechos de propiedad en la cuestión crucial de los medicamentos, en la medida que ello pudiera conducir a una limitación en el acceso a los mismos. Es el caso de Argentina, que tuvo vigente durante más de 100 años, la ley 111 de patentes del año 1864, que descartaba explícitamente al patentamiento de productos farmacéuticos. Bajo esta eximición, prosperó en el país una extendida industria de especialidades medicinales, que no estuvo obligada al reconocimiento de derechos de 
propiedad al proceder a la copia de diversas formulaciones. Este tipo de excepciones regía en diversos países en vías de desarrollo.

Los ADPIC surgieron con el nacimiento mismo de la Organización Mundial de Comercio (OMC) la cual, a su turno, fue fundada con el objetivo de reforzar el disciplinamiento del comercio internacional a los países centrales.

Al relacionar los derechos de propiedad con el comercio internacional, los ADPIC pretendieron poner fin, de un modo drástico, a las "fugas" que los países en desarrollo pretendían preservar en relación al cumplimiento de las normas de patentamiento. Debe recordarse en este punto que la OMC se ha constituido bajo el principio del "todo único”, que obliga a los países firmantes a acatar sin excepción al conjunto de los acuerdos establecidos. De este modo, si un miembro de la OMC quiere acceder a los beneficios de los acuerdos de libre comercio, se encuentra obligado a acatar las normas relacionadas con patentes y propiedad industrial. Los ADPICs establecieron un régimen de transición para los países en desarrollo que expiró en 2005, aunque para los de menor desarrollo relativo se extendió hasta el 2016 en el caso de las patentes farmacéuticas. La única "ventana" que permitió una excepción al reconocimiento de patentes residió en la conocida cláusula de los ADPICs que admite la producción libre de medicamentos patentados por razones de "emergencia nacional". Aludiendo a esta cláusula, Brasil desarrolló una importante provisión de las combinaciones antiretrovirales para el tratamiento del HIV, sin pagar por ello derechos de patentes a sus formuladores originales.

El caso más crítico que expuso el conflicto entre la salud pública y las normas de los ADPIC tuvo lugar en Sudáfrica, en el proceso que derivó en el llamado "juicio de Pretoria”. En 1997, bajo la presión de la pandemia del HIV, el gobierno sudafricano resolvió legalizar la importación de drogas "copiadas" para el tratamiento del HIV, en vistas de que, a los precios reclamados por las multinacionales de medicamentos, se hubiera tornado presupuestariamente inviable para el país. En efecto: mientras el tratamiento característico con las combinaciones antirretrovirales presentaba un costo de 10 a 15.000 dólares por ańo, el salario medio en Sudáfrica no superaba entonces los 3.000 dólares anuales. La importación de estos medicamentos desde aquellos países que habían logrado sortear las disposiciones de la OMC -como Brasil o India-le implicaba a Sudáfrica un costo por paciente veinte veces menor que el reclamado por las multinacionales del sector. Aunque Sudáfrica alegó también las razones de "emergencia sanitaria" admitidas por la OMC, debió enfrentar sin embargo un juicio impulsado por 39 laboratorios internacionales, alegando, precisamente, que el país estaba violando los ADPIC de la OMC. El desarrollo del juicio fue el escenario de movilizaciones multitudinarias de afectados en la propia Sudáfrica, pero también de demostraciones de solidaridad de comunidades similares de diferentes países del mundo. Como resultado de esta presión internacional, los laboratorios que habían iniciado el litigio terminaron sometidos a una fuerte interpelación de la opinión pública mundial, constituyendo un caso piloto en términos del conflicto entre ética y propiedad privada del conocimiento. Finalmente, y como resultado de esta presión, los laboratorios terminaron retirando la demanda contra el país y se avinieron a un acuerdo con el gobierno sudafricano. A través del mismo, éste mantenía su reconocimiento de principios sobre el régimen de patentes y las normas ADPIC; pero los laboratorios admitían la importación de "copias" baratas como un hecho excepcional, asociado a la pandemia del virus HIV en el país y en la región subsahariana, que reunía en ese entonces al $75 \%$ de las 30 millones 
de personas infectadas en el mundo. Muy pronto, países como Ghana, Uganda y la República Dominicana siguieron el camino de Sudáfrica.

En Argentina, el reconocimiento de los ADPICs condujo a la modificación de la legislación vigente en materia de patentes medicinales, y cuya anterior flexibilidad había dado lugar a una importante industria de laboratorios nacionales. Precisamente, en 1996 se promulga la ley 24.572, redactada para adaptar el marco normativo del país a las exigencias de los ADIPC. La ley sancionada en 1996 admite explícitamente el patentamiento de productos farmacéuticos, en tres variantes precisas: las invenciones de productos (desarrollo de nuevos principios activos); de procedimiento (procesos) y de uso, en este caso, allí donde se descubran nuevas aplicaciones para un producto conocido.

Los ADPICs refrendaron el régimen de protección de la actividad inventiva durante 20 años. Sin embargo, y como hemos afirmado anteriormente, es conocida la práctica de las grandes corporaciones farmaceúticas para prolongar artificialmente la vigencia de esta protección, por la vía de introducir modificaciones menores en la formulación de las especialidades medicinales, registrarlas luego como si fuera una innovación sustantiva y, por esa vía, asegurar un nuevo período de protección de 20 años ( “me too").

De un modo general, y este es el caso casi excluyente en los países en desarrollo, la investigación en especialidades medicinales tiene lugar en el ámbito de organismos vinculados al Estado o a la universidad pública. De ese modo, el "núcleo duro", y aún no rentable, de las investigaciones resulta financiado por el Estado y, a través de él, por los contribuyentes que son los usuarios potenciales de las especialidades medicinales a desarrollar. Sin embargo, cuando las investigaciones colocan a los productos en un status comercial, el régimen de patentamiento transfiere todos los potenciales beneficios de la investigación al capital privado. Al mismo tiempo, la creación de un monopolio sobre el producto del conocimiento se convierte en un factor limitante de su difusión al conjunto de la población. Paradójicamente, la misma que, con sus impuestos, había contribuido a financiar su desarrollo inicial. 
urgentes para el "acceso a los medicamentos esenciales", dado que el "precio, en particular en el sector privado, representa una barrera clave al acceso de los medicamentos esenciales”. Más recientemente, otros acuerdos comerciales multilaterales, como el Tratado Trans Pacifico (TTP) han instituidos normas restrictivas relacionadas con la producción de medicamentos.

Este conjunto de normas ha creado un escenario caracterizado por dos polos antagónicos. De un lado, tenemos a la población de los países en desarrollo castigada por males endémicos y, sin embargo, curables. Del otro, se encuentran los beneficios extraordinarios de los monopolios farmacéuticos. Pero aparece acá otra dicotomía: esos mismos países en desarrollo, privados del acceso a medicamentos como resultado de este régimen de rentas monopólicas, son los que "aportan" a la industria el material humano de los ensayos clínicos, los cuales, como vimos oportunamente, tienen lugar sin asegurarle a quienes participan de los mismos las más elementales garantías, en relación a sus derechos personales y su seguridad sanitaria. Además son realizados en instituciones públicas.

La cuestión del patentamiento, y en particular de los medicamentos, pone de manifiesto uno de los antagonismos más vivos del orden social contemporáneo, cuyo norte es el lucro privado. Mientras ese régimen económico y social aboga por la "libre competencia" y el funcionamiento pleno de las leyes mercantiles, no vacila en imponer un monopolio a través de mecanismos institucionales - de eso se trata la legislación de patentes. Es indudable que el reencuentro entre la ciencia y la salud humana exige abolir esa contradicción: si la ciencia es el resultado de un largo proceso social y colectivo, sus resultados también deben ser objeto de una reapropiación social.

\section{Bibliografía}

—Allard Soto, Raúl. (2015) Revista Redbioética/UNESCO, Año 5, 2 (10): 51-63, julio-diciembre, 2014, ISSNvol. 11, $\mathrm{N}^{\circ}$ 1 [citado 2016-11-25], pp. 9-21 "Medicamentos esenciales y Acuerdo sobre los ADPIC: colisión entre el derecho a la salud y el derecho de propiedad intelectual", Salud colect. [online], recuperado en: http://www. scielo.org.ar/scielo.php?script=sci_arttext\&pid=S1851- 82652015000100002\&ln$\mathrm{g}=\mathrm{es} \& \mathrm{nrm}=\mathrm{iso}$.

— Bécourt D. (1990) La Revolución Francesa y el derecho de autor: por un nuevo universalismo. Pág 6. Boletín de Derechos de Autor de la UNESCO, Volumen XXIV. Recuperado en: https://www.la-rida.com/en/ article-rida-en/1864?lang=en Acuerdo sobre los Aspectos de los Derechos de Propiedad Intelectual relacionados con el Comercio. (Abril 1994) Capítulo 5, artículo 31, inc. (b) Recuperado en: https://www.wto.org/ spanish/tratop_s/trip

- Bécourt D. (1990) “La Revolución Francesa y el derecho de autor: por un nuevo universalismo". Pág 6. Boletín de Derechos de Autor de la UNESCO, Volumen XXIV. Recuperado en: https://www.la-rida.com/ en/article-rida-en/1864?lang=en Robinson, J. (1958) "The Accumulation of Capital", p.87, citado en F.Machlup, "An economic Review of the Patent System, p.40, Washington, Government Printing Office, y por Katz J. (op.cit). ISSN 1851-8265.

- EFE|ELMUNDOSA-LUD.COM. "Las farmacéuticas retiran su demanda contra el Gobierno sudafricano", (abril, 2001). Recuperado en: https://www.elmundo. es/elmundosalud/2001/04/19/medicina/987672183.html

— Homedes, A.; Ugalde, N. (2007) América Latina: la Acumulación de Capital, la Saludy el Papel de las Instituciones Internacionales. Recuperado en: http://www.redalyc.org/ articulo.oa?id=73130103 
— Homedes, A. Ugalde, N. (20011) Cuatro palabras sobre ensayos clínicos: ciencia/negocio, riesgo/beneficio. Recuperado en: http://www.redalyc.org/ articulo.oa?id=73122320002

—Katz,J. (1976) Capítulo VI: "Patentes, inventores independientes y corporaciones multinacionales en el marco de la actividad manufacturera argentina". Importacion de tecnologia, aprendizaje e industrialización dependien-te. Buenos Aires: Fondo de Cultura Económica

— Katz, Jorge. (1997) "El escenario farmacéutico y farmoquímico en los países desarrollados",Cap. 1 de Apertura y desregulación en el mercado de medicamentos, Jorge Katz (ed.). Buenos Aires: CEPAL/IDRC, Alianza, 1.

—Katz, J. (1976) Capítulo VI: "Patentes, inventores independientes y corporaciones multinacionales en el marco de la actividad manufacturera argentina". En: Importación de tecnología, aprendizaje e industrialización dependiente. Buenos Aires: Fondo de Cultura Económica

- Machlup, F. y Penrose, E. (1950, Mayo) "The patent controversy in the 19th Century", Journal of Economic History (10) 1-29.

-Vidal, S. (2006) "Etica o mercado. Una decisión urgente. Lineamientos para el diseño de normas éticas en investigaciones biomédicas en América Latina". En: Keyeux, G.; Penchaszadeh, V.; Saada, A. (orgs.), Investigación en seres humanos y políticas de salud pública. Bogotá: Unibiblos. 